\title{
Is there a "continental" view of health economics evaluation?
}

\author{
Claude Le Pen
}

Published online: 1 January 2009

(C) Springer-Verlag 2008

Without any doubt, the United Kingdom's National Institute for Health and Clinical Excellence (NICE) was ground-breaking in incorporating health economics into health technology assessment (HTA) at the official leveli.e. not only in academic circles. Furthermore, NICE elaborated an exact doctrine, stating very precise methodological guidance [1] that is generally regarded in the "economic HTA market" (drug companies, consultancy companies, experts, etc.) as "state-of-the art". These principles are well known and can easily be summarised. The recommended type of analysis is cost-utility; health benefits should be measured preferably in terms of qualityadjusted life-years (QALYs); utility incorporated in QALYs should be derived preferably from "choice based methods"; preferences should be those of the general population; cost computation should be made from the National Health Service (NHS) perspective; both costs and health effects should be discounted at an annual rate of $3.5 \%$ and QALYs are not to be weighted according to patients' characteristics [1].

Following the United Kingdom's lead, other countries have created independent HTA agencies. For example, in Germany, the German Institute for Quality and Efficiency in Health Care (Institut für Qualität und Wirtschaftlichkeit im Gesundheitswesen, IQWiG) was created as part of the 2003 reform, and in France the Haute Autorité de Santé (HAS) was created as part of the 2004 reform. Both became effective as of 1 January 2006. However, while both these latter agencies support the mission statement of promoting "efficiency" in health care, and both have created health economics departments, neither has agreed to

C. Le Pen $(\bowtie)$

University of Paris-Dauphine, 75016 Paris, France

e-mail: claude.lepen@dauphine.fr follow NICE methodological principles for economic evaluation, while at the same time they both refer to the same "evidence based medicine" (EBM) HTA principles. Moreover, they explicitly state that they will not use QALYs to assess health benefits and will not use cost-utility thresholds to formulate treatment guidelines or reimbursement recommendations.

So the question arises: why? Why are medical HTA principles universal while economic HTA principles are not? The standard answer is: because of "cultural differences"! Decision makers are not theoretical economists and must take the local cultural background into account. But this answer remains too vague. What are these "cultural factors"? I would suggest here two "cultural" factors, the first being historical in nature, the other resting on philosophical considerations.

The first reason is linked to the classical distinction between NHS-based systems and social insurance-based systems, that is, the difference between so-called "Beveridgian" and "Bismarckian" systems. Although the difference between them has tended to fade over time, peoples' behaviour and representations still rest on some of the basic principles underlying these systems. The key point is that rationing health care was an accepted and established practice in the British NHS before NICE was created and before health economics was officially used as a way to rationalise this practice. The basic NHS principle was to give access to free care (at point of delivery) to everyone, with funding by general taxation. The basic French "Sécurité Sociale" principle was to allow the poor to have access to the same care as the rich, by means of a mandatory health insurance system jointly financed by employees and employers. Rationed access to care was a "genetic" feature of NHS systems as a counterpart to universality and absence of direct payment; unlimited 
access to care was a "genetic" feature of social insurance systems, as a counterpart to the adherence of trade-unions, especially those influenced by the French communist party, to a reformist view of society. Thus, the social contracts underlying the two systems are different.

So, in the United Kingdom, the introduction of health economic evaluation appeared as an intelligent way to rationalise rationing, the opportunity cost theory giving an intellectual content to a pre-existing policy, while in France it appeared-and still appears-as a way of introducing rationing. This big difference, which is deeply rooted in the social history of both countries, largely explains the opposition of the two models regarding drugs use and reimbursement recommendations. The NICE model is based on a trade-off between efficiency and cost, expressed in the form of a cost-utility ratio and a threshold for acceptance, while the French model is a two-tier lexicographic model: a decision is first made based solely on clinical evidence; a price is then negotiated (or fixed) at a level that is as low as possible (the limit being the point at which the manufacturer does not launch the productwhich sometimes happens). Efficiency is not traded against cost (at least officially). This allows French authorities to present the system as not rationing and to transfer to the manufacturers the responsibility of launching their product, or not, at the regulated price.

The second reason is more philosophical and relates to dominant conceptions of illness, health and medicine. Medical thinking on the continent is largely influenced by philosophers or social scientists that have long been practically unknown in English-speaking nations. Conversely, the utilitarian philosophy that underlies the QALY construction $^{1}$, and which is relatively popular in Englishspeaking countries, is almost completely banned from the cultural background of the continental elite, especially in the medical and political milieu. I would suggest that these influences play a role in the rejection of (or the reluctance to adopt) the so-called "Anglo-Saxon" methods of assessing health care.

Let us illustrate this point by the example of Georges Canguilhem (1904-1995), a philosopher and physician who published his masterpieces ${ }^{2}$ at a time when the English-speaking epistemology was dominated by the logical

\footnotetext{
${ }^{1}$ QALYs are not only the multiplication of years of life by utility coefficients. They are themselves utilities (or utility functions with life expectancy and quality of life as arguments) in the sense that the theory assumes that a health state is to be preferred to another one if, and only if, it "produces" more QALYs. This was made clear by Pliskin et al. [2]. Moreover, QALYs are used as cardinal, interpersonally comparable and additive utilities.

${ }^{2}$ Essentially his 1943 dissertation, Le Normal et le Pathologique, translated as The Normal and the Pathological by Carolyn R. Fawcett \& Robert S. Cohen (New York: Zone Books, 1991, fourth printing 1998).
}

positivism that is in polar opposition to Canguilhem's Kantian, historical and critical epistemology.

I cannot here enter into the details of Canguilhem's thesis, which was influenced greatly by German philosophy and has been described as part of a "continental epistemology" [3]. I would simply state that his work is devoted to criticising the "positivist" view that health and illness differ only in quantitative terms, and that illness consists of quantitative departures, by excess (hyper-) of by default (hypo-), from a "norm" that defines health and which may receive a quantitative expression, for instance a glycaemia rate. Canguilhem defines health not as a norm but as the possibility to act on the environment, to "normalise" the environment, to create norms of living corresponding to an individual's physical and mental state. Normality is not the absence of illnesses (it is normal to be ill from time to time) but the capacity to overcome illness. And illness (especially chronic illness) is a certain way of living just as health is. This is why Canguilhem's philosophy is sometimes described as a "rational vitalism". Life blows into sickness just as it does in health; the difference lies in the norms of life that structure both states.

Canguilhem's view of pathology thus resembles Amartya Sen's-another opponent to utilitarianism-view of poverty. The poor are not the rich with less money ${ }^{3}$; the sick are not the healthy with less health. Both the poor and the sick reconstruct their living norms at the level of their possibilities, expectations and hopes. The choice sets are disjoint, thus it makes no sense to measure the preferences of the sick over items that do not belong to their universe. The consequence is a holistic view of the sick person considering all dimensions of his life and not only those of an altered organ. The consequence is also a humanist view of medicine, where the medicine of the sick is preferred over the medicine of the illness.

It is easy to understand how badly the welfarist conception of QALYs fits with this philosophy, which is hugely influential among social researchers in France (especially through the works of Michel Foucault, a student of Canguilhem), and has been disseminated and discussed in Germany and Italy.

Of course, Canguilhem's purpose was not to provide tools with which to allocate resources to competing ends. But had he been confronted with this question, he would certainly have refuted QALYs; he would have considered them as a false rationalisation consisting of reducing individuals to figures and plotting health states on a single

\footnotetext{
${ }^{3}$ Sen rejects the quantitative view of poverty: "The income-centred view of poverty, based on an interpersonally invariant "poverty line income', may be very misleading in the identification and evaluation of poverty". Poverty is a certain combination of "capabilities" and "functioning's", of "doings and beings", and not only deprivation of income. See for instance: [4]. This can be applied literally to the sick.
} 
dimensional scale ranging from full health to death. According to Canguilhem, this would ignore the notion that illness and health are different and not comparable ways to organise life and thus cannot be plotted in the same space. There is no continuum among health states and each of them generates its own pattern of functionalities, quality and values. They are not comparable just as individual utilities are not comparable because they refer to different perceptions of good and bad.

Of course, choices have to be made in a world of scarce resources. But not, Canguilhem would have suggested, from a criterion that assumes normatively that an improvement in a symptom score has the same meaning and the same value to each individual, irrespective of his peculiar physical, mental and social state. Maybe he would have preferred to rely pragmatically on case-by-case negotiation, which does not need any unifying assumption between the values of the sick and those of the healthy. In that case, he would have been in keeping with the way many public decision makers do think and act on the continent, and maybe also elsewhere.

\section{References}

1. NICE. Guide to the methods of technology appraisal, April 2004. National Institute for Health and Clinical Excellence, London (2004)

2. Pliskin, J., Shepard, D., Weinstein, M.: Utility function for life years and health status. Ops. Res. 28, 206-224 (1980) NICE

3. Rheinberger, H.-J.: Reassessing the historical epistemological epistemology of Georges Cangulihem. In: Gutting, G. (ed.) Continental Philosophy of Science. Blackwell, Oxford (2005)

4. Gaertner, W.: Amartya Sen: Capability and well-being. In: Nussbaum, M.C., Sen, A. (eds.)The Quality of Life. Clarendon, Oxford (1993) 